\title{
On Studying the Interrelationship amongst Possible Factors Affecting Biomedical Waste Management in Health Care SMEs
}

\author{
Veena Aggarwal \\ Recventure Education \\ Services Private Limited \\ Delhi, India
}

\author{
Sanjana Bhat \\ Medical Centre, BITS \\ Pilani Pilani, Rajasthan \\ India
}

\author{
V. K. Aggarwal \\ Recventure Education \\ Services Private Limited \\ Delhi, India
}

\author{
Remica Aggarwal \\ MIT-SOER, MIT- ADT \\ University \\ Pune, India
}

\begin{abstract}
Biomedical waste management (BMW) is one of the biggest challenges of the present day times because it has a direct impact on the health of human beings. Since it contains infectious and hazardous materials, its safe and proper disposal is extremely important. It is crucial on the part of the employees to know the hazards of the biomedical waste in the work environment and make its disposition effective and in a scientific manner. It is therefore important that related professionals should have adequate education , knowledge , attitudes as well as practices with respect to biomedical waste management. Present research work is on first identifying the various factors involved in bio-medical waste management in health care centers and SMEs and thereafter it tries to explore the possible inter-relationship amongst them using ISM methodology.
\end{abstract}

\section{Keywords}

Bio-medical waste ; ISM methodology ; Health care SMEs ; Incineration, Solid waste, Hazardous, Non-hazardous

\section{INTRODUCTION}

Health care waste is a unique category of waste by the quality of its composition, source of generation, its hazardous nature and the need for appropriate protection during handling, treatment and disposal. Mismanagement of the waste affects not only the generators, operators but also the common people too. 'Bio-medical waste' (BMW) means any solid and/or liquid waste including its container and any intermediate product, which is generated during the diagnosis, treatment or immunization of human beings or animals or in research pertaining thereto or in the production or testing thereof. ${ }^{2}$ Bio-medical waste management is becoming a major issue not only in hospitals and nursing homes but also to the environment. The waste generated from a hospital is a potential health hazard to the health care workers, patients, hospital visitors, public and flora and fauna of the area.

After the Ministry of Environment, Forest and Climate Change of India released the Bio-Medical Waste Management Rules, it is now a legal requirement to safely dispose biomedical waste. But the rules are hardly implemented in practice as hospitals are still disposing waste in a haphazard, improper and discriminate manner. Lack of segregation practices can cause mixing of bio-waste with general waste making the whole waste stream hazardous. Also lack of awareness and improper handling of waste contribute towards armful aftermaths and implications on their health including transmission of diseases like typhoid, cholera, hepatitis and AIDS etc. India approximately generates $2 \mathrm{~kg} / \mathrm{bed} / \mathrm{day}^{3}$ and this biomedical waste encompasses wastes like anatomical waste, cytotoxic wastes, sharps, which when inadequately segregated could cause different kinds of deadly infectious diseases like Human immunodeficiency virus(HIV) hepatitis $\mathrm{C}$ and $\mathrm{B}$ infections etc. ${ }^{4}$ and also cause disruptions in the environment, and adverse impact on ecological balance. ${ }^{5,6}$

It has been estimated that up to $85 \%$ to $90 \%$ of the waste generated in hospitals is non-infectious (free with any body fluids, which is similar to domestic waste) . It is the remaining $10 \%$ to $20 \%$ of waste that is of concern because it is hazardous and infectious. In addition, waste that is unsegregated and not treated in the right manner would cause environmental pollution affecting the health of the community. For example , the improper disposal of biomedical waste can cause air pollution (in the form of air pollutants such as chemical pollutants due to open burning and incinerators ). Similarly, it can cause water pollution due to harmful chemicals present in the heavy metals. Land Pollution is caused by the final disposal of all bio-medical waste. Even liquid effluent after treatment is spread on land. Hence, pollution caused to land is inevitable. Open dumping of bio-medical waste is the greatest cause for land pollution.

If properly designed and applied, waste management can be a relatively effective and an efficient compliance-related practice. Proper collection and segregation of biomedical waste are important. Adequate knowledge amongst the health care employees about the biomedical waste management rules and regulations, and their understanding of segregation, will help in the competent disposal of the waste in their respective organizations. ${ }^{7}$ Within a health care facility or hospital, the main groups submitted to risks are doctors, medical nurses, patients, visitors, workers in ancillary services, service workers dealing with waste treatment and disposal of health unit. Regarding the health care workers, three infections are most commonly transmitted: hepatitis B virus (HBV), hepatitis $\mathrm{C}$ virus $(\mathrm{HCV})$, and human immune-deficiency (HIV) virus. Hence adequate knowledge, attitudes and practices of the staff of the health care institutes play a very important role. ${ }^{8,4}$ Teaching institutes play a critical role in the health care setup as it is from these places that the future health care professionals and all those persons involved in the care giving to the community are trained. ${ }^{10}$

Although the solid waste management has become one of the major topics of importance but still local bodies are unable to give the proper attention towards some special sources of wastes out of which biomedical waste is one. The sources of biomedical waste can be categorized as primary and secondary sources according to the quantities produced. 
Sources of biomedical waste are hospitals, labs research centres, blood banks and nursing homes. Although the present research work utilizes the data through exploration of the related researches with the help of various search engines such as Google scholar, Wikipedia, Scopus etc. The information is searched through books, journals as well as magazines to ensure the comprehensiveness and effective analysis.

Objectives of the present study is therefore many folds :

1) To study the mechanism of bio-medical waste management;

2) To highlight the challenges faced while ensuring biomedical waste management in India and

3) To study the inter-relationships amongst the various challenges with the help of ISM methodology.

Present research work therefore studies the various challenges involve in the bio-medical waste management in health care SMEs. Thereafter, it tries to study the interrelationship amongst them using ISM methodology .

\section{LITERATURE REVIEW ${ }^{1-6}$}

Some of the common challenges faced by a health care SME $\mathrm{s}$ are as follows :

1. Limited or Lack of Knowledge and awareness (LKA) : The knowledge component of the doctors was more desirable compared to their practices whereas vice-versa was true for nurses and lab technicians. The knowledge component was low amongst the housekeeping staff; which was identical to the results from other similar studies conducted previously. ${ }^{10,13,16}$. The questions on knowledge appraised the participant's knowledge on attributes related to the color coding and their implications, identification of biomedical hazard symbol, waste categories, and hospital policies for biomedical waste management.

2. Attitude of higher management towards BMW management and house- keeping staff (AHM) : The attitude towards BMW management of housekeeping staff was low. Usually it is diagnosed through interview questions such as: The questions on attitude were related to matters like, was biomedical waste hazardous, its management additional burden on their work or if their appropriate management burden on the finances of the hospital, and also on legislative measures for waste management.

3. Lack of training and education(LTE) : Low level of knowledge was mainly attributed to new staff coming on rotation to the hospital and also to comparably low educational levels of the housekeeping staff. Training of all cadres of staff will help in the analytical evaluations for suitable and applicable management of biomedical waste. ${ }^{10,13,16}$ The questions on practice appraised if the study respondents had received any training on biomedical waste management, if they were immunized against hepatitis B and if disinfection of sharps were carried out at the point of generation.

4. Poor practice of recapping the needles (PPRN) : The practice of recapping the needles was very low across cadres. Recapping of needles is one of the important risk factor for needle stick injuries; the prevalence was very low in the organization. This may be associated to the awareness of the staff and also due to the adequate number of needle cutters in the various patient care areas of the hospital.

5. Improper Employee Time \& Inefficiency of the Biomedical waste handling process (IETIE): Laziness and inefficiency could be a major barrier in the ineffective disposal of bio-medical waste .

6. Patient Safety (PS): maintaining of quality and patient safety is an important challenge .

7. Employee Safety (ES) : improper rendering of safety to workers and staff of healthcare SME s results in improper and risky disposal of biomedical waste

8. Waste segregation process (WSP): Waste segregation process at source in operation theatre and other areas is an important challenge before the related staff of bio medical waste

9. Handling of overall wet waste (HWW): It can lead to disposal of hazardous chemicals, infectious agents, antimicrobial residues getting discharged in hospital wastewater, groundwater and surface water.

10. Lack of apathy(LoA) : to the concept of waste management is a major barrier towards the effective bio-medical waste management practices. An effective communication strategy is imperative keeping in view the low awareness level among different category of staff in the health care establishments regarding biomedical waste management.

\section{INTERPRETIVE STRUCTURAL MODELLING METHODOLOGY}

Interpretive structural modelling methodology or ISM [14] is a known technique to map the relationships amongst the relevant elements as per decision maker's problems in a hierarchical manner. Starting with the identification of elements, it proceeds with establishing the contextual relationships between elements (by examining them in pairs ) and move on towards developing the structural selfinteraction (SSIM) matrix using VAXO [14] and then initial reachability matrix and final reachability matrix and rearranging the elements in topological order using the level partition matrices. A Mic-Mac analysis is performed afterwards which categorize the variables as per the driving and dependence power in to autonomous, dependent, driver and linkage category. Finally, a diagraph can be obtained.

\section{DEVELOPMENT OF ISM MODEL CASE EXAMPLE}

Challenges described in the above section are being further studied for the possible inter-relationships amongst them. These are Limited or Lack of Knowledge and awareness (LKA); Attitude of higher management towards BMW management and house- keeping staff (AHM); Lack of training and education (LTE); Poor practice of recapping the needles (PPRN); Improper Employee Time \& Inefficiency of the Biomedical waste handling process (IETIE); Patient Safety risk (PSR) ; Employee Safety risk (ES); Problematic waste segregation process (PWSP) ; problematic handling of 
overall wet waste (PHWW); Lack of apathy(LoA).

\subsection{Construction of Structural self-}

\section{interaction Matrix (SSIM)}

This matrix gives the pair-wise relationship between two

\begin{tabular}{|c|c|c|c|c|c|c|c|c|c|c|c|}
\hline $\begin{array}{c}\text { S. } \\
\text { No. }\end{array}$ & Barriers & 1 & 2 & 3 & 4 & 5 & 6 & 7 & 8 & 9 & 10 \\
\hline 1 & LKA & & L & A & V & V & V & V & V & V & V \\
\hline 2 & AHM & & & V & V & V & V & V & V & V & V \\
\hline 3 & LTE & & & & V & V & V & V & V & V & V \\
\hline 4 & PPRN & & & & & X & V & V & V & V & V \\
\hline 5 & IETIE & & & & & & V & V & V & V & V \\
\hline 6 & PSR & & & & & & & X & A & A & A \\
\hline 7 & ESR & & & & & & & & A & A & A \\
\hline 8 & PWSP & & & & & & & & & X & A \\
\hline 9 & PHWW & & & & & & & & & & A \\
\hline 10 & LoA & & & & & & & & & & \\
\hline
\end{tabular}

Fig 1: SSIM matrix for pair wise relationship amongst barriers

\subsection{Construction of Initial Reachability}

\section{Matrix and final reachability matrix}

The SSIM has been converted in to a binary matrix called the initial reachability matrix shown in fig. 2 by substituting V, A, variables i.e. I and $j$ based on VAXO. SSIM has been presented below in Fig 1 .

\begin{tabular}{|c|c|c|c|c|c|c|c|c|c|c|c|}
\hline $\begin{array}{c}\text { S. } \\
\text { No. }\end{array}$ & Barriers & 1 & 2 & 3 & 4 & 5 & 6 & 7 & 8 & 9 & 10 \\
\hline & & LKA & AHM & LTE & PPRN & IETIE & PSR & ESR & PWSP & PHWW & LoA \\
\hline 1 & LKA & 1 & 0 & 0 & 1 & 1 & 1 & 1 & 1 & 1 & 1 \\
\hline 2 & AHM & 1 & 1 & 1 & 1 & 1 & 1 & 1 & 1 & 1 & 1 \\
\hline 3 & LTE & 1 & 0 & 1 & 1 & 1 & 1 & 1 & 1 & 1 & 1 \\
\hline 4 & PPRN & 0 & 0 & 0 & 1 & 1 & 1 & 1 & 1 & 1 & 1 \\
\hline 5 & IETIE & 0 & 0 & 0 & 1 & 1 & 1 & 1 & 1 & 1 & 1 \\
\hline 6 & PSR & 0 & 0 & 0 & 0 & 0 & 1 & 1 & 0 & 0 & 0 \\
\hline 7 & ESR & 0 & 0 & 0 & 0 & 0 & 1 & 1 & 0 & 0 & 0 \\
\hline 8 & PWSP & 0 & 0 & 0 & 0 & 0 & 1 & 1 & 1 & 1 & 0 \\
\hline 9 & PHWW & 0 & 0 & 0 & 0 & 0 & 1 & 1 & 1 & 1 & 0 \\
\hline 10 & LoA & 0 & 0 & 0 & 0 & 0 & 1 & 1 & 1 & 1 & 1 \\
\hline
\end{tabular}

Fig 2: Initial reachability matrix

$\mathrm{X}, \mathrm{O}$ by 1 or 0 as per the case. After incorporating the transitivity, the final reachability matrix is shown below in the Fig 3. 


\begin{tabular}{|c|c|c|c|c|c|c|c|c|c|c|c|c|}
\hline $\begin{array}{c}\text { S. } \\
\text { No. }\end{array}$ & Barriers & 1 & 2 & 3 & 4 & 5 & 6 & 7 & 8 & 9 & 10 & D.P \\
\hline & & LKA & AHM & LTE & PPRN & IETIE & PSR & ESR & PWSP & PHWW & LoA & \\
\hline 1 & LKA & 1 & 0 & 0 & 1 & 1 & 1 & 1 & 1 & 1 & 1 & 8 \\
\hline 2 & AHM & 1 & 1 & 1 & 1 & 1 & 1 & 1 & 1 & 1 & 1 & 10 \\
\hline 3 & LTE & 1 & 0 & 1 & 1 & 1 & 1 & 1 & 1 & 1 & 1 & 9 \\
\hline 4 & PPRN & 0 & 0 & 0 & 1 & 1 & 1 & 1 & 1 & 1 & 1 & 7 \\
\hline 5 & IETIE & 0 & 0 & 0 & 1 & 1 & 1 & 1 & 1 & 1 & 1 & 7 \\
\hline 6 & PSR & 0 & 0 & 0 & 0 & 0 & 1 & 1 & 0 & 0 & 0 & 1 \\
\hline 7 & ESR & 0 & 0 & 0 & 0 & 0 & 1 & 1 & 0 & 0 & 0 & 1 \\
\hline 8 & PWSP & 0 & 0 & 0 & 0 & 0 & 1 & 1 & 1 & 1 & 0 & 4 \\
\hline 9 & PHWW & 0 & 0 & 0 & 0 & 0 & 1 & 1 & 1 & 1 & 0 & 4 \\
\hline 10 & LoA & 0 & 0 & 0 & 0 & 0 & 1 & 1 & 1 & 1 & 1 & 5 \\
\hline De.P & & 3 & 1 & 2 & 5 & 5 & 10 & 10 & 8 & 8 & 6 & \\
\hline
\end{tabular}

Fig 3 : Final reachability matrix

D.P : Driving power ; De.P : dependence power

\subsection{Level Partition}

From the final reachability matrix, reachability and final antecedent set for each factor are found. The elements for which the reachability and intersection sets are same are the top-level element in the ISM hierarchy. After the identification of top level element, it is separated out from the other elements and the process continues for next level of elements. Reachability set, antecedent set, intersection set along with different level for elements have been shown below in table 4 .

Table 4.3.1: Iteration I

\begin{tabular}{|c|c|c|c|c|}
\hline $\begin{array}{c}\text { S.No } \\
\text {.No }\end{array}$ & $\begin{array}{c}\text { Reachabili } \\
\text { ty set }\end{array}$ & $\begin{array}{c}\text { Antecedent } \\
\text { set }\end{array}$ & $\begin{array}{c}\text { Intersect } \\
\text { ion set }\end{array}$ & Level \\
\hline $\mathbf{1 .}$ & $\mathbf{6 , 7}$ & $\begin{array}{c}\mathbf{1 , 2 , 3 , 4 , 5 , 6 , 7 , 8} \\
\mathbf{, 9 , 1 0}\end{array}$ & $\mathbf{6 , 7}$ & I \\
\hline 2. & $6,7,8,9$ & $\begin{array}{c}1,2,3,4,5,8,9,1 \\
0\end{array}$ & $\mathbf{8 , 9}$ & II \\
\hline 3. & $\begin{array}{c}6,7,8,9,10 \\
1,2,3,4,5,10\end{array}$ & $\mathbf{1 0}$ & III \\
\hline 4. & $\begin{array}{c}4,5,6,7,8,9, \\
10\end{array}$ & $1,2,3,4,5$ & $\mathbf{4 , 5}$ & IV \\
\hline 5. & $\begin{array}{c}1,4,5,6,7,8, \\
9,10\end{array}$ & $1,2,3$ & $\mathbf{1}$ & $\mathbf{V}$ \\
\hline 6. & $\begin{array}{c}1,3,4,5,6,7, \\
8,9,10\end{array}$ & 2,3 & $\mathbf{3}$ & VI \\
\hline 7. & $\begin{array}{c}1,2,3,4,5,6, \\
7,8,9,10\end{array}$ & 2 & $\mathbf{2}$ & VII \\
\hline
\end{tabular}

\subsection{Classification of factors}

The critical success factors described earlier are classified in to four clusters viz. autonomous factor, dependent factors, linkage factors and independent / Driving factors are mentioned below.

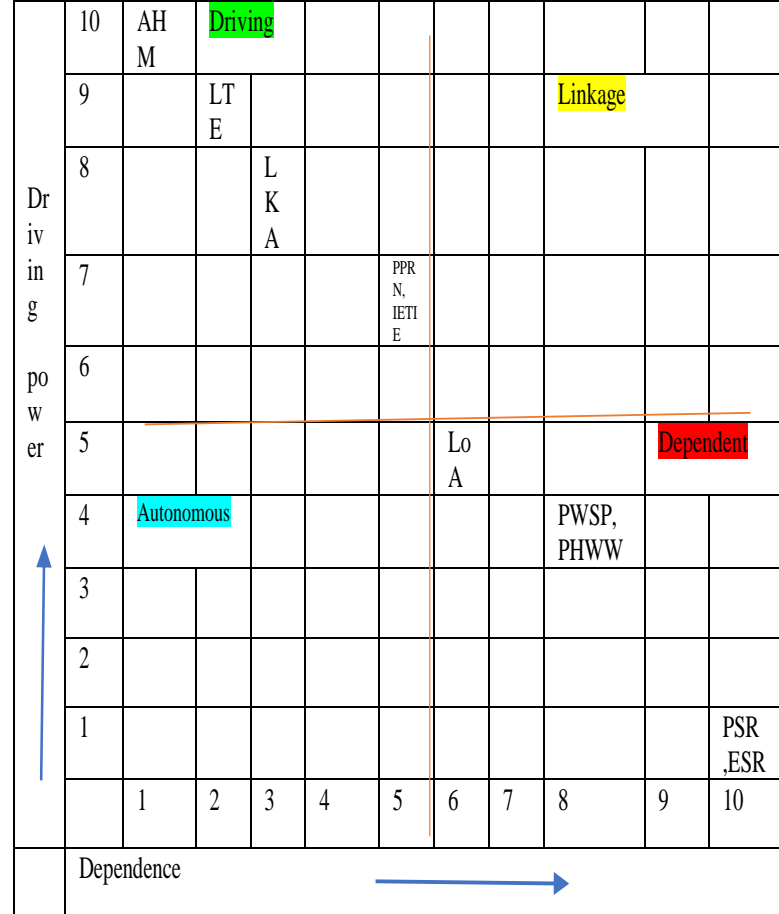

Fig. 4.Driving Power and Dependence Diagram

\subsection{ISM model}

An ISM model is developed ( as shown in fig. 5 below ) after arranging the elements as per their interaction or dependence relationships. 


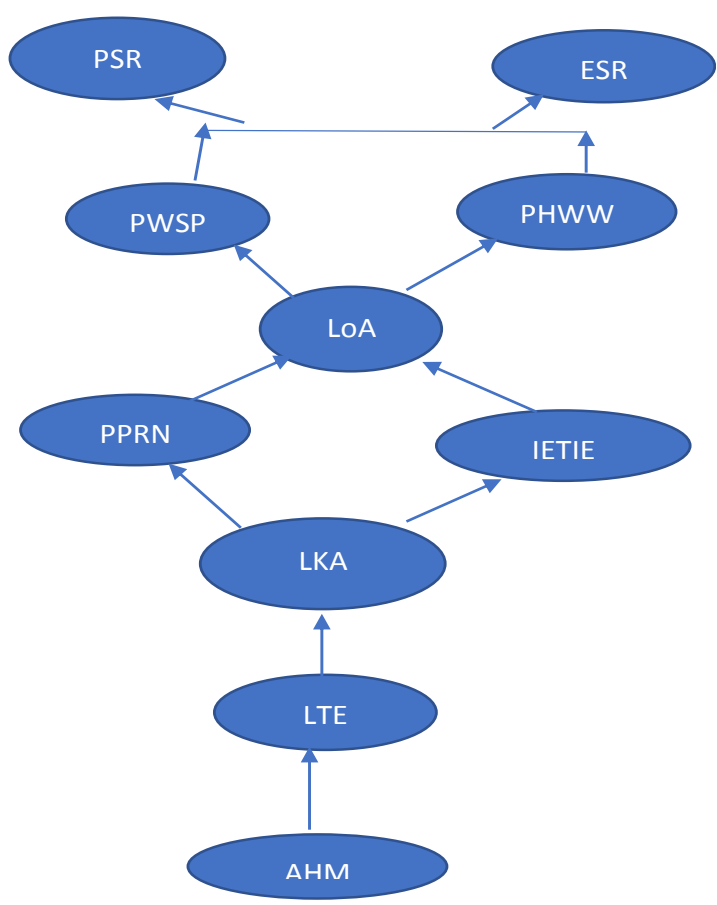

Fig 5 : ISM Model

\section{LITERARY OBSERVATIONS AND RECOMMENDATIONS}

- Hospital Management must understand the gravity of the issue and they must be able to ensure proper identification, segregation at the source of generation, collection in prescribed colour containers, safe transportation, appropriate treatment and environmentally sound disposal of Bio-Medical Waste.

- They should also provide health education and training of everyone involved in the management and handling of Bio-Medical Waste.

- Last but not the least is effective implementation of rules by surprise visits and inspection by appropriate authorities and fixing the accountability of each and every person involved in management of Bio- Medical Waste.

\section{ACKNOWLEDGMENTS}

Our thanks to the anonymous reviewers whose comments have helped us in improving the manuscript . Co-author Remica Aggarwal also pay her sincere regards to Prof. S.P Singh of DMS , IIT Delhi for disseminating the knowledge about ISM methodology.

\section{REFERENCES}

[1] Kumar P.V.A.G, Kapate R. 2012. Knowledge, Attitude, and Practices of Health Care Waste Management amongst Staff of Nursing Homes of Gulbarga City. Journal of Pharmaceutical and Biomedical Sciences. 19(19), 1-3.

[2] Sharma A.K. Biomedical Waste (Management and Handling) Rules. First edition. Bhopal. Suvidha Law House. 12.

[3] Patil A.D, Shekdar A.V. 2001. Health-care waste management in India. J Environ Manage. 63, 211-20.
[4] Nath, P.A, Prashanthini, V., Visvanathan, C. 2010. Healthcare waste management in Asia. Waste Management.30, 154-61.

[5] Lakshmikantha, H. 2006. Report on waste dump sites near Bangalore. Waste management. 26(6), 640-50.

[6] Misra, V., Pandey, S.D. 2005. Hazardous waste, impact on health and environment for development of better waste management strategies in future in India. Environment International. 31, 417-31.

[7] Kini, B.S, Kumar S, Reddy M, Nabar A.S, Kamath V.G, Kamath A, Eshwari K. 2014. Knowledge, Attitudes and Practices regarding Biomedical Waste Management among staff of a tertiary healthcare centre in coastal Karnataka. J Pub Health Med Res.2(1), 20-4.

[8] Pattnaik S, Reddy M.V. 2010. Assessment of Municipal Solid Waste management in Puducherry (Pondicherry). India. Resources, Conservation and Recycling. 54, 512-20.

[9] Mathur V, Dwivedi S, Hassan M.A, Misra R.P. 2011. Knowledge, Attitude, and Practices about Biomedical Waste Management among Healthcare Personnel: A Cross-sectional Study. Indian J Community Med. 36, 143-5.

[10] Radha R. 2012. Assessment of existing knowledge, attitude, and practices regarding biomedical waste management among the health care workers in a tertiary care rural hospital. Int J Health Sci Res. 2(7), 14-19.

[11] Verma L.K, Mani S, Sinha N, Rana S. 2008. Biomedical waste management in nursing homes and smaller hospitals around Delhi. Waste Management. 28, 272334.

[12] Kumar S, Bhattacharyya J.K, Vaidya A.N, Chakrabarti T, Devotta S, Akolkar A.B. 2009. Assessment of the status of solid waste management in metro cities, state capitals, class I cities, and class II towns in India: An insight. Waste Management. 29, 883-95.

[13] Pandit N.B, Mehta H.K, Kartha G.P, Choudhary S.K. 2005. Management of biomedical waste: Awareness and practices in a district of Gujarat. Indian J Public Health. $49,245-7$

[14] Rao P.H. 2008. Report: Hospital waste management awareness and practices: A study of three states in India. Waste Manage Res. 26, 297-303.

[15] Kishore J, Goel P., Sagar B., Joshi T.K. 2000 Awareness about biomedical waste management and infection control among dentists of a teaching hospital in New Delhi, India. Indian J Dent Res.11, 157-61.

[16] Saini S., Nagarajan S.S, Sarma R.K. 2005. Knowledge, Attitude and Practices of Bio-Medical Waste Management Amongst Staff of a Tertiary Level Hospital in India. Journal of the Academy of Hospital Administration. 17(2).

[17] Yadavannavar, M.C., Berad , A.S., Jagirdar, P.B. 2010. Biomedical waste management: A study of knowledge, attitude, and practices in a tertiary health care institution in Bijapur. Indian Journal of Community Medicine. 35(1), 170-71.

[18] Rao, D. , Dhakshaini, M.R. , Kurthukoti, A. and Doddawad ,V.G. Biomedical waste management: a 
study on assessment of knowledge, attitude and practices among health care professionals in a tertiary care teaching hospital. http://dx.doi.org/10.13005/bpj/1543

[19] Improving the Management of Waste and Generating Revenue. Aravind Eye Care Hospitals, Pondicherry

[20] Rao, D., Dhakshaini, M. R., Kurthukoti, A., Doddawad, V. G. 2018. Biomedical Waste Management: A Study on Assessment of Knowledge, Attitude and Practices Among Health Care Professionals in a Tertiary Care Teaching Hospital. Biomedical Pharmacology Journal . 11(3).

[21] Capoor, M.R. and Bhowmik, K.T. 2017. Implementation challenges in bio-medical waste management rules, 2016. 35(4), 623-625.

[22] Chhetri , H. 2017 . Bio-medical waste managementchallenges in India , Proceedings of International Conference 2017, Organized by TMIMT Moradabad.

[23] Warfield, J. N. 1974. Developing interconnection matrices in structural modeling. IEEE Transactions on System, Man, and Cybernetics, SMC-4 (1), 81-87.

\section{Appendix}

A1 : Mandate of Bio medical waste management (BMWM) Rules -2016 [Capoor et al. 2016]

As per the mandate of the BMWM rules, 2016, only pretreatment (few articles) and segregation (all kinds of BMW) is required at the HCF level, and the final disposal and recycling (Government authorised recyclers) is mandated at common bio-medical waste treatment facility (CBMWTF) level. As per the BMWM rules 2016, there are 4 color coded categories of yellow, red, white and blue. To curtail the Pilferage of sharps (needles), a mutilation preferably with a needle cutter is required on site, before transportation to central common waste site and final disposal by CBMWTF.

As per the BMWM rules 2016, records of yearly BMWM training, health check-up, immunization, equipment etc. need to be maintained for about five years. The pre-treatment of laboratory waste, micro-biology waste, blood bags by sterilization is recommended by autoclave, microwave or hydroclave. The definite shortcomings include the nonavailability of PVC free blood bags. The inability of the most of available effluent treatment technologies in removing antimicrobial residues needs to be addressed. For barcoding, the draft guidelines by the Central Pollution Control Board (CPCB)2017 are available (http://cpcb.nic.in/Bio_medical.php). The grey areas or novel waste which is generated but not documented in rules should have a buyback policy or should be treated as per recommended guidelines of Centers for Disease Control and Prevention or the World Health Organization. The challenges in the BMWM rules 2016 will be gradually overcome with the guidelines and handbooks released from state pollution control committee, $\mathrm{CPCB}, \mathrm{MoEF}$ and $\mathrm{CC}$ from time to time

(http://cpcb.nic.in/Bio_medical.php;

www.dpcc.delhigovt.nic.in).

It has become obligatory on all the stakeholders HCF,
CBMWTF, inspecting agencies, the pharmaceutical industry, households, civil societies involved in BMWM to delve into the scientific aspect of BMWM and come up with definitive, targeted and practical ways under the existing rules of the country to save the environment from hazards. Furthermore, sustainable development goal 12.4 states that by 2020 countries should achieve the environmentally sound management of waste throughout their life cycle, in accordance with agreed frameworks (https://sustainabledevelopment.un.org).

\section{Appendix A2 : Treatment and disposal techniques for biomedical waste [22]}

There are several methods that have been successful in the treatment of infectious waste :

\section{Autoclave}

Autoclaves are closed chambers that apply both heat and pressure, and sometimes steam, over a period of time to sterilize medical equipment. Autoclaves have been used for nearly a century to sterilize medical instruments for reuse. Autoclaves can be used to process up to $90 \%$ of medical waste, and are easily scaled to meet the needs of any medical organization. Small counter-top autoclaves are often used for sterilizing reusable medical instruments while large autoclaves are used to treat large volumes of medical waste.

\section{Incineration}

This is proved in which there is increase temperature causes dry oxidation. To reduce organic \& combustible waste to inorganic incombustible to reduce volume \& weight that cannot be reveled, reused or disposed in outer land field. The drawbacks to incineration include the large capital and operating costs for modern technologies. The waste should be less moisture as less than $30 \%$ and also combustible.

\section{Thermal inactivation}

Thermal inactivation involves the treatment of waste with high temperatures to eliminate infectious agents. This method is usually used for large volumes. Liquid waste is collected in

vessel and heated by heat exchangers or a steam jacket surrounds the vessel. The types of pathogens in the waste determine the temperature and duration of treatment. After treatment, the contents can be discharged into the sanitary sewer in a manner that complies with State, Federal, and local requirements.

\section{Gas/vapor sterilization}

Gas/vapor sterilization uses gaseous or vaporized chemicals as the sterilizing agents. Ethylene oxide is the most commonly used agent, but should be used with caution since it is suspected human carcinogen.

\section{Chemical disinfection}

Chemical disinfection is the preferred treatment for liquid infectious wastes. The factors such as type of microorganism, Degree of contamination, Amount of protein acetous material present, type of disinfectant, temperature, $\mathrm{pH}$, mixing requirements, and the biology of the microorganism etc. are considered while chemical disinfection. Ultimate disposal of chemically treated waste should be in accordance with State and local requirements. 